\section{INCREASED LEVELS OF ENDOTHELIN-1 IN BRONCHOALVEOLAR LAVAGE FLUID OF PATIENTS WITH LUNG ALLOGRAFTS}

The aim of the present study was to determine levels of endothelin-1 in bronchoalveolar lavage fluid and in plasma in patients with lung and heart-lung allografts. The aim was based on the hypothesis that levels of endothelin-1 are elevated in the bronchoalveolar lavage fluid of patients with lung allografts. Patients $(n=23)$ undergoing heart-lung $(n=8)$, single-lung ( $n=10)$, or bilateral lung $(n=5)$ transplantation were included in the study. In patients with single-lung allografts, endothelin-1 levels were analyzed in bronchoalveolar lavage fluid from both the transplanted and the nontransplanted, native lung. The level of endothelin-1 was also analyzed in bronchoalveolar lavage fluid from 12 patients who did not undergo transplantation. Transbronchial biopsies and bronchoalveolar lavage were done routinely or when clinically indicated on 64 different occasions, between 2 and 104 weeks after transplantation. The level of endothelin-1 was measured in bronchoalveolar lavage fluid and plasma by radioimmunoassay. Immunoreactive endothelin-1 was detectable in bronchoalveolar lavage fluid from all patients. The concentration of endothelin-1 in bronchoalveolar lavage fluid from transplanted lungs $\mathbf{( 2 . 9 4} \pm \mathbf{0 . 3 0}$ $\mathrm{pg} / \mathrm{ml}, n=64$ ) was significantly higher compared with that in bronchoalveolar lavage fluid from patients without allografts $(0.86 \pm 0.20 \mathrm{pg} / \mathrm{mI}, \boldsymbol{n}=$ $12, p<0.01$ ). In patients who received single-lung transplantation because of emphysema, the level of endothelin-1 in bronchoalveolar lavage fluid from the transplanted lung was significantly greater than that from the native lung $(5.61 \pm 1.9$ versus $0.39 \pm 0.05 \mathrm{pg} / \mathrm{ml}, p<0.05)$. Concentrations of endothelin-1 in bronchoalveolar lavage fluid did not correlate with grade of rejection, infection, or time after transplant. Plasma levels of endothelin-1 were unchanged with pulmonary rejection. These results indicate that endothelin-1 is released into bronchi of transplanted human lungs. The release is not associated with rejection or infection. Because of its potent mitogenic properties, endothelin-1 may have a potential impact in the development of posttransplant complications such as bronchiolitis obliterans. (J Thorac CaRdiovasc SuRg 1996;111:253-8)

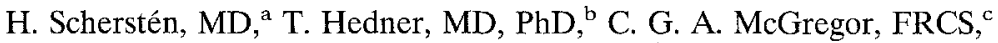
V. M. Miller, $\mathrm{PhD},{ }^{\mathrm{c}}$ G. Mårtensson, $\mathrm{MD}, \mathrm{PhD},{ }^{\mathrm{d}}$ G. C. Riise, $\mathrm{MD}, \mathrm{PhD},{ }^{\mathrm{d}}$ and F. N. Nilsson, $\mathrm{MD}, \mathrm{PhD},{ }^{a}$ Gothenburg, Sweden, and Rochester, Minn.
Endopt ndothelin-1 (ET-1) is a bioactive 21-amino-acid peptide produced by vascular endothelial cells, ${ }^{1}$ bronchial epithelium, ${ }^{2,3}$ and mononuclear cells such

From the Divisions of Cardiothoracic Surgery, ${ }^{a}$ Clinical Pharmacology, ${ }^{\mathrm{b}}$ and Pulmonary Medicine, ${ }^{\mathrm{d}}$ Sahlgrenska University Hospital, Gothenburg, Sweden, and the Departments of Surgery and Physiology and Biophysics, ${ }^{\mathrm{c}}$ Mayo Clinic and Foundation, Rochester, Minn.

Presented in part at the First International Congress on Lung Transplantation, Paris, France, Sept. 8-9, 1994.

Supported by grants from The Göteborg Medical Society and The Swedish National Society Association Against Heart and Lung Diseases. as macrophages and lymphocytes. ${ }^{4}$ In addition to causing bronchoconstriction and vasoconstriction it is also a mitogen and stimulates vascular smooth muscle and fibroblasts to proliferate. ${ }^{5-8}$ The effects of ET-1 could therefore be associated with in-

Received for publication Jan. 3, 1995.

Accepted for publication April 12, 1995.

Address for reprints: Henrik Scherstén, MD, Division of Cardiothoracic Surgery, Sahlgrenska University Hospital, S-413 45 Göteborg, Sweden.

Copyright (C) 1996 by Mosby-Year Book, Inc.

$0022-5223 / 96 \$ 5.00+0 \quad \mathbf{1 2 / 1 / 6 5 5 4 0}$ 
Table I. Clinical data

\begin{tabular}{lrlc}
\hline \multicolumn{1}{c}{ Diagnosis } & $n$ & $\begin{array}{c}\text { Transplantation } \\
\text { procedure }\end{array}$ & $\begin{array}{c}\text { Mean age } \\
\text { in years } \\
\text { (range) }\end{array}$ \\
\hline Eisenmenger syndrome & 5 & Heart-lung & $21(16-31)$ \\
Emphysematous disease & 10 & Single lung & $49(36-56)$ \\
Primary pulmonary hy- & 3 & Bilateral lung & $47(33-56)$ \\
$\quad$ pertension & 2 & Heart-lung & $35(21-46)$ \\
Cystic fibrosis & 1 & Bilateral lung & \\
Bronchiectases & 2 & Heart-lung & $34(16-52)$ \\
Dilated cardiomyopathy & & &
\end{tabular}

creased airway pressure and vascular resistance observed during acute lung allograft rejection and with the development of bronchiolitis obliterans, which is the most serious threat to long-term survival in lung recipients. $^{9}$

In patients with symptomatic asthma ${ }^{10}$ and patients with interstitial lung disease ${ }^{11,12}$ ET-1 is increased in bronchoalveolar lavage (BAL) fluid. ET-1 levels also increase in BAL fluid during acute rejection in dogs with allografts, an effect that is reversible with antirejection therapy. ${ }^{13}$ ET-1-like immunoreactivity in vascular endothelial and bronchial epithelial cells is increased in human transplanted lungs during acute rejection. ${ }^{14}$ Therefore there is strong evidence that pulmonary dysfunction and disease are accompanied by increased release of ET-1, and the hypothesis of this study is that ET-1 levels are elevated in BAL fluid of patients with lung allografts. The aim of this study was to systematically measure ET- 1 in BAL fluid and in plasma from human lung transplant recipients and to determine whether the content of ET-1 correlated with episodes of rejection or infection. ET-1 was also investigated in BAL fluid from subjects who did not undergo transplantation or operation.

\section{Patients and methods}

During the period November 1991 to December 1993, 23 patients undergoing bilateral lung $(n=5)$, heart-lung $(n=8)$, or single-lung $(n=10)$ transplantation were included in the study. The patients' ages ranged from 16 to 56 years with a mean age of 39 years (Table I). Nine patients were female and 14 were male. A control group consisting of 12 patients (10 smokers, 2 ex-smokers) admitted to the hospital because of symptoms of bronchitis was selected for the study.

Oral consent was obtained from all patients before their participation in the study. The study was approved by the Ethics Committee of the Medical Faculty, University of Göteborg.

Donors and recipients were matched by cytomegalovirus (CMV) serologic status. All organs were harvested in a similar fashion. The heparinized donor was given an infusion of $20 \mathrm{ng} / \mathrm{kg}$ per minute of prostacyclin (prostaglandin $\mathrm{I}_{2}$, Flolan) directly into the pulmonary artery until systemic blood pressure dropped by approximately $30 \%$.

Pulmonary preservation was then achieved by infusion of a cold flushing solution into the donor pulmonary artery $(60 \mathrm{ml} / \mathrm{kg}$ body weight). The flushing solution consisted of Euro-Collins solution to which was added 16 mmol magnesium sulfate and $20 \mu \mathrm{g}$ of prostacyclin per liter of solution After the donor organ was removed it was stored in cold Ringer's solution $\left(4^{\circ} \mathrm{C}\right)$. All procedures used the same technique for extraction and implantation, with a running suture of nonabsorbable monofilament used for the airway and vascular anastomoses. In the single and bilateral lung procedures, the bronchial anastomosis was wrapped with an intercostal muscle pedicle. Extracorporeal circulation was necessary for intraoperative cardiopulmonary support in three patients undergoing bilateral transplantation.

Immunosuppression. Patients received preoperative immunosuppression therapy with a loading dose of cyclosporine A (6 to $8 \mathrm{mg} / \mathrm{kg}$ ) and azathioprine $(4 \mathrm{mg} / \mathrm{kg}$ ) orally. In addition rabbit antithymocyte globulin (Pasteur Merieux, $2.5 \mathrm{mg} / \mathrm{kg}$ ) was used for induction immunosuppression on 3 to 5 consecutive days. Methylprednisolone was given intravenously $(500 \mathrm{mg}$ at reperfusion followed by $125 \mathrm{mg}$ every 8 hours $\times 3$ ) and then continued by enteral administration of prednisone at a dosage of 0.3 $\mathrm{mg} / \mathrm{kg}$ per day tapered to $0.2 \mathrm{mg} / \mathrm{kg}$ per day 1 month after operation. Cyclosporine A was given between 12 and 24 hours after transplantation by continuous intravenous infusion at a dosage adjusted to maintain serum levels of 300 to $400 \mu \mathrm{g} / \mathrm{L}$ (by radioimmunoassay specific for whole blood, Cyclotrac, Incstar, Minn.). As soon as enteral function had normalized, cyclosporine $\mathrm{A}$ was administered orally. Azathioprine was given orally once a day (2 $\mathrm{mg} / \mathrm{kg}$ ) and adjusted to maintain an absolute number of blood neutrophils greater than $3 \times 10^{9} / \mathrm{L}$.

Episodes of acute rejection were treated with methylprednisolone $(1 \mathrm{gm})$ intravenously for 3 days and antithymocyte globulin therapy was reinstituted if rejection was resistant to steroid treatment or was particularly severe. Patients in the control group were not receiving medication and therefore were free from immunosuppressive drugs.

Postoperative follow-up. Transbronchial biopsies (TBBs) and BAL were done routinely at 2 and 4 weeks after transplantation and thereafter monthly for the first 3 months. Additionally bronchoscopic studies with TBB and BAL were done 6,9 , and 12 months after transplantation or whenever indicated by clinical parameters such as dyspnea, hypoxemia, decline in forced expiratory volume in 1 second, radiographic infiltrate, or unexplained fever. Repeat TBB and BAL were done approximately 3 weeks after treated rejection episodes.

The histopathologic diagnosis of rejection was determined by TBB and graded according to the international working formulation for classifying and grading pulmonary rejection. ${ }^{15}$

BAL analyses included direct microscopy for CMV (intranuclear inclusions), Pneumocystis carinii (Gomori's silver stain), fungus, and mycobacteria and immunofluorescence microscopy for Pneumocystis carinii, Legionella 
Table II. ET-1 content in BAL fluid during episodes of acute rejection and infection in lung and heart-lung transplant recipients

\begin{tabular}{lrc}
\hline & & $\begin{array}{c}\text { ET-1 } \\
\text { content } \\
(p g / m l)\end{array}$ \\
\hline Acute rejection & 32 & $2.87 \pm 0.35$ \\
Grade 1 & 6 & $3.27 \pm 0.70$ \\
Grade 2 & 18 & $2.25 \pm 0.49$ \\
Grade 3 & 8 & $3.10 \pm 0.70$ \\
CMV pneumonitis & 5 & $2.71 \pm 0.54$ \\
Bacterial infections & 6 & $2.97 \pm 0.27$ \\
Pseudomonas & 1 & 3.90 \\
Enterococci & 1 & 2.20 \\
Staphylococcus epidermidis & 2 & 2.70 \\
Escherichia coli & 1 & 3.51 \\
Legionella & 1 & 2.83 \\
No rejection/no infection & 24 & $3.09 \pm 0.53$ \\
\hline
\end{tabular}

pneumophilia, and respiratory syncytial virus. Polymerase chain reaction analysis was done for $\mathrm{CMV}^{16}$ and culture for bacteria including legionella and mycobacteria, fungus, and virus. Bacterial cultures were taken routinely from blood, the nasopharynx, and urine.

Study protocol. Patients were anesthetized with intravenously given propofol and the tip of the bronchoscope was wedged into two segmental bronchi of the lung. Saline solution $(140 \mathrm{ml})$ warmed to body temperature was flushed into the bronchus. Approximately 60 to $100 \mathrm{ml}$ of the fluid was aspirated through the suction channel of the bronchoscope and $10 \mathrm{ml}$ was collected in chilled tubes containing ethylenediaminetetraacetic acid $(1 \mathrm{mg} / \mathrm{ml})$ and aprotinin $(300 \mathrm{U} / \mathrm{ml})$, immediately transported on ice to the laboratory, and centrifuged at $4^{\circ} \mathrm{C}, 500 \mathrm{gm}$, for 10 minutes. The supernatant was removed with a pipette and frozen at $-70^{\circ} \mathrm{C}$ for later analysis.

TBB procedures were done after collection of BAL fluid. Biopsy specimens were taken from different sites within one lung with an alligator forceps: 4 to 6 specimens were taken, immediately placed in $10 \%$ buffered formalin, and sent for histologic analyses.

At the time of bronchoscopy a venous blood sample was taken for analysis of plasma ET-1.

Radioimmunoassay of ET-1. Immunoreactive ET-1 was measured with use of a double antibody kit (Amersham, RPA 545, Amersham, United Kingdom) that has $100 \%$ crossreactivity with ET-1 and ET-2. No crossreactivity was observed with ET-3 or big endothelin. The lowest detectable concentration for the assay was 0.33 $\mathrm{fmol} / \mathbf{1 0 0} \mathrm{ml}$.

Statistical analyses. The results are expressed as means plus or minus the standard error of the mean. In all experiments, $n$ equals the number of samples of lavage fluid and blood samples obtained. Analysis of variance was used to compare means among the groups. When a significant F value was found, a Scheffe's test was used to identify differences among means. Values were considered to be statistically different when $p<0.05$.

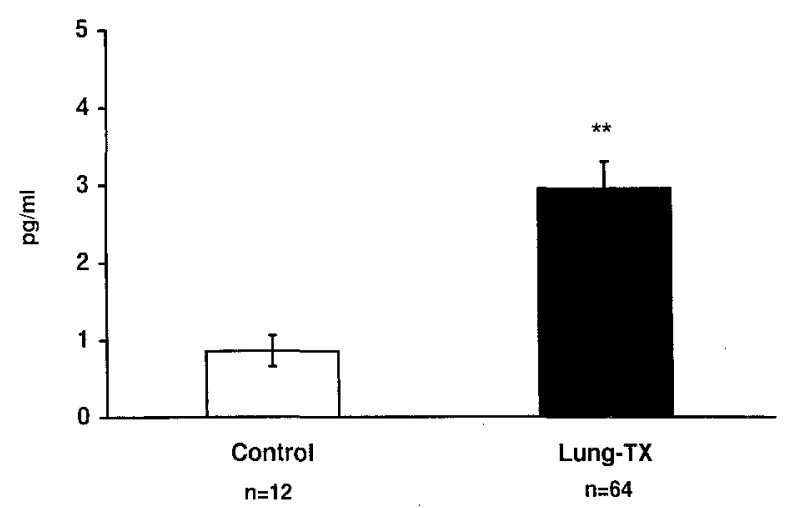

Fig. 1. ET-1 content in BAL fluid from patients who underwent lung transplantation (Lung-TX) and control group. Levels of ET-1 were significantly increased in patients with allografts compared with those in control group. ${ }^{* *} p<0.01$.

\section{Results}

There were no deaths during the study period. In the 23 patients who underwent transplantation BAL fluid was analyzed on 64 different occasions. Patients underwent study on at least at two different occasions (mean 2.8, range 2 to 6 tests per patient) between 2 and 104 weeks after transplantation. There were 32 histopathologically diagnosed acute rejection episodes, six episodes of bacterial infection, and five CMV pneumonitis episodes (Table II).

ET-1 in BAL fluid. ET-1 was detectable in BAL fluid from all patients who underwent transplantation. ET-1 levels remained consistently high in all patients with a mean ET-1 content of $2.94 \pm 0.35$ $\mathrm{pg} / \mathrm{ml}$ from the transplanted lungs. This was significantly higher than ET-1 levels in the BAL fluid in the control group of patients who did not undergo transplantation ( $0.86 \pm 0.20 \mathrm{pg} / \mathrm{ml}, p<0.01)$ (Fig. 1).

In seven single-lung transplant recipients the content of ET-1 in the transplanted lungs was significantly higher than that in the native, unoperated contralateral lung $(5.60 \pm 1.91$ versus $0.39 \pm 0.05$ $\mathrm{pg} / \mathrm{ml}, p<0.05$, Fig. 2). The content of ET-1 in BAL fluid did not correlate either with the presence of rejection episodes or with the degree of acute rejection (Table II). There were no differences in ET-1 levels from the patients with allografts who had ongoing CMV infection and bacterial infections compared with levels in the absence of infection (Table II).

Notably, the content of ET-1 in BAL fluid in patients who underwent transplantation remained 


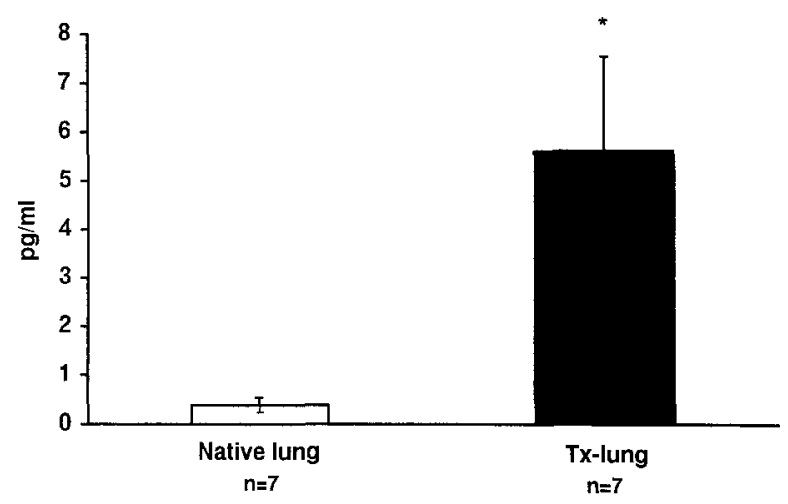

Fig. 2. ET-1 content in BAL fluid from patients who underwent single-lung transplantation. Samples were taken both from native, unoperated lung and from transplanted lung (Tx-lung). ET-1 levels were significantly increased in transplanted lungs compared with those in native lungs. * $p<0.05$.

high and did not decrease during the study period (Fig. 3).

ET-1 in plasma. The plasma level of ET-1 during episodes of acute rejection in 11 patients with lung allografts was $1.87 \pm 0.22 \mathrm{pg} / \mathrm{ml}$. During conditions of no rejection in the same 11 patients plasma ET-1 levels were $2.24 \pm 0.27 \mathrm{pg} / \mathrm{ml}$, which were not different from levels obtained during acute rejection. No plasma samples were obtained from the control patients.

\section{Discussion}

Results of this study demonstrate that levels of ET-1 are increased in BAL fluid from transplanted lung allografts. Further, ET-1 levels in lavage fluid do not decrease with time after transplantation and there is no correlation between rejection or infection of the transplanted lung and levels of ET-1 in BAL fluid.

ET-1 levels are elevated in BAL fluid from acutely rejecting lung allografts in dogs and pigs ${ }^{13,17}$ and in rejecting lung tissue from human transplanted lungs. ${ }^{14}$ Therefore it is reasonable to believe that there is a pathophysiologic significance of the increased ET-1 levels in transplanted lungs. However, the role of ET-1 as a marker of immunologic expression is not clear. In two experimental animal studies there was a correlation between acute rejection of the transplanted lung and release of ET- 1 in BAL fluid. ${ }^{13,17}$ In the present study no such correlation was found between rejection and ET-1 levels. This could be explained by differences among species and the fact that in the animal studies lung

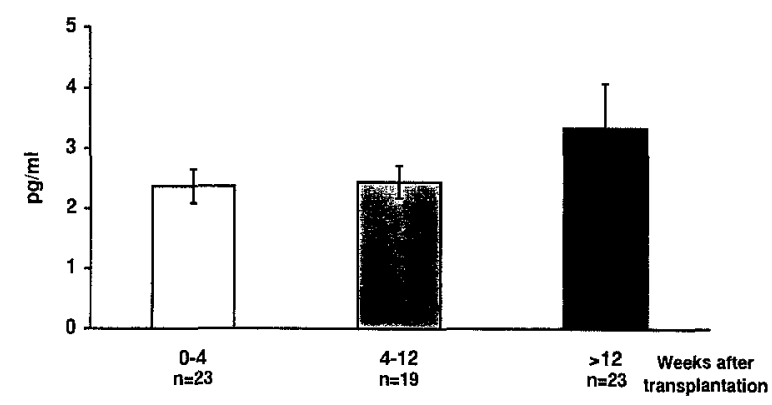

Fig. 3. ET-1 content in BAL fluid from patients who underwent lung transplantation during time course after transplantation ranging from 2 to 104 weeks after transplantation. No significant changes in ET-1 levels were demonstrated during study period.

rejection was unmodified, inasmuch as animals were not receiving immunosuppressive treatment to modify rejection. In our study all patients were given immunosuppressive treatment continuously, which may have altered the degree and nature of ET-1 release.

ET-1 is a bronchoconstrictor and vasoconstrictor of potential pathophysiologic importance in several lung disorders such as asthma ${ }^{10,18}$ and cryptogenic fibrosing alveolitis. ${ }^{12}$ In guinea pigs low doses of ET-1 enhance the sensitivity of bronchial contractions to histamine. ${ }^{19}$ Similarly, patients with transplanted lungs have airway hyperactivity when they are exposed to histamine and exacerbation of these responses occurs during acute rejection. ${ }^{20,21}$ Therefore airway resistance and hyperactivity in patients with transplanted lungs may be associated with increased airway levels of ET- 1 and the peptide could have a potential impact in triggering bronchoconstriction.

ET-1 possesses mitogenic properties and studies have shown that ET-1 is a mitogen for fibroblasts and acts synergistically to amplify the response of these cells to other growth factors. ${ }^{22,23}$ The consistently elevated levels of ET-1 from the lung allografts in the present study whether or not rejection or infection was present may suggest that ET-1 could be associated with fibroblast proliferation and subsequently the development of bronchiolitis obliterans.

The origin of ET-1 in BAL fluid is unclear but several sources are possible such as epithelial cells, ${ }^{12,24}$ vascular endothelium, ${ }^{1}$ macrophages, ${ }^{4}$ and alveolar type 2 pneumocytes. ${ }^{12}$ The purpose of this study was not to investigate the pulmonary origin of ET-1 per se. However, the most likely 
sources are from epithelial cells or inflammatory cells such as macrophages, which are the dominating cell population in BAL fluid and are known to synthesize and release ET-1. ${ }^{4}$ Because plasma levels of ET-1 among the patients in this study who underwent transplantation were low and comparable with the range found in healthy, nonoperated subjects, ${ }^{25}$ it is most likely that ET-1 is produced from activated immunocompetent inflammatory cells particularly localized in the transplanted lung.

Glucocorticoids can induce release of ET-1. ${ }^{26}$ This cannot likely explain the increased levels of ET-1 because there was no correlation between ET-1 levels and the dose of corticosteroids given to the patients who underwent transplantation. Furthermore, in dogs subjected to single-lung transplantation 6 days of treatment with high-dose steroids after acute lung allograph rejection decreased BAL fluid levels of ET-1 instead of increasing the release of the hormone. ${ }^{13}$

The release of ET- 1 into the bronchial lumen may be the final step in a series of reactions in which a continuous inflammatory process with activation of inflammatory mediators such as adhesion molecules and cytokines is present. Recently, a study showed that human lung allographs demonstrate expression of the cellular adhesion molecule in alveolar epithelium and vascular endothelium both in conditions of acute allograft rejection and when patients are free from rejection. ${ }^{27}$ These findings support the hypothesis that a continuous activation of the immune system is present in the transplanted lung whether rejection is current or not. This hypothesis is supported by the fact that in our patients who underwent single-lung transplantation ET-1 levels from the native, unoperated lungs were low and these lungs were not under immunoresponse stress. In the future, drugs that prevent the continuous immunoresponse activation may be a new therapeutic option to the classic triple-drug (steroids, cyclosporine A, azathioprine) regimen of patients who receive lung transplantation.

In conclusion, this study demonstrates a continuous release of ET-1 from the transplanted lung in patients with lung and heart-lung allografts. No correlation was found between BAL fluid levels of ET-1 and acute lung allograft rejection or bacterial or viral infection. Because ET-1 is a bioactive peptide with strong mitogenic properties the development of bronchiolitis obliterans by fibroblast proliferation may in part be explained by the presence of the peptide in airways of lung transplant recipients.

\section{REFERENCES}

1. Yanagisawa M, Kurihara H, Kimura S. A novel potent vasoconstrictor peptide produced by vascular endothelial cells. Nature 1988;332:411-5.

2. Uvhida Y, Ninomiya H, Saotome M. Endothelin, a novel vasoconstrictor peptide, as potent bronchoconstrictor. Eur J Pharmacol 1988;154:227-9.

3. Mattoli S, Mezzetti M, Riva G, Allegra L, Fasoli A. Specific binding of endothelin on human bronchial smooth muscle cells in culture and secretion of endothelin-like material from bronchial epithelial cells. Am J Respir Cell Mol Biol 1990;3:145-51.

4. Ehrenreich H, Anderson RW, Fox $\mathrm{CH}$, et al. Endothelins, peptides with potent vasoactive properties, are produced by human macrophages. J Exp Med 1990;172:1741-8.

5. Dubin D, Pratt RE, Cooke JP, Dzau VJ. Endothelin, a potent vasoconstrictor, is a vascular smooth muscle mitogen [Abstract]. J Vasc Med Biol 1989;1:150.

6. Simonson MS, Jones JM, Dunn MJ. Differential regulation of fos and jun gene expression and AP-1 cis-element activity by endothelin isopeptides. J Biol Chem 1992;267:8643-6.

7. Simonson MS, Dunn MJ. Endothelin: pathways of transmembrane signaling. Hypertension 1990;15:1-5.

8. Ricagna F, Miller VM, McGregor CGA. Mitogenic activity of endothelin-1 in canine lung organ cultures [Abstract]. Clin Res 1993;41:149A.

9. Report of the St. Louis International Lung Transplant Registry, Cooper JD. St. Louis: April 1994.

10. Mattoli S, Soloperto M, Marini M, Fasoli A. Levels of endothelin in bronchoalveolar lavage fluid of patients with symptomatic asthma and reversible airflow obstruction. J Allergy Clin Immunol 1991;88:376-84.

11. Sofia M, Mormile M, Faraone S, et al. Increased endothelin-like immunoreactive material on bronchoalveolar lavage fluid from patients with bronchial asthma and patients with interstitial disease. Respiration 1993;60:89-95.

12. Giaid A, Michel RP, Stewart DJ, Sheppard M, Corrin B, Hamid Q. Expression of endothelin-1 in lungs of patients with cryptogenic fibrosing alveolitis. Lancet 1993;341:1550-4.

13. Schersten H, Aarnio P, McGregor CGA, Miller VM. Endothelin-1 is increased in bronchoalveolar lavage fluid from rejecting canine allotransplanted lungs. Transplantation 1994;57:159-61.

14. Giaid A, Shennib H. Endothelin-1-like immunoreactivity in the human transplanted lung [Abstract]. Eur Respir J 1993;6(suppl):17:364s.

15. Yousem SA, Berry GJ, Brunt EM, et al. A working formulation for the standardization of nomenclature in the diagnosis of heart and lung rejection: lung rejection study group. J Heart Transplant 1990;9:593601.

16. Studahl M, Ricksten A, Sandberg T, Elowsson S, 
Bergström T. Cytomegalovirus encephalitis in four immunocompetent patients. Lancet 1992;340:1045-6.

17. Aarnio P, Hämmäinen P, Fyhrquist F, Harjula A. Endothelin content of bronchoalveolar lavage fluid from allotransplanted pigs is increased during unmodified rejection. J THORAC CaRdiovasC SuRg 1994;107:216-9.

18. Vittori E, Marini M, Fasoli A, De-Franchis R, Mattoli S. Increased expression of endothelin in bronchial epithelial cells of asthmatic patients and effects of corticosteroids. Am Rev Respir Dis 1992;146(5 Pt 1):1320-5.

19. Kanazawa H, Kurihara N, Hirata K, Fujiwara H, Matsushita H, Takeda T. Low concentration endothelin-1 enhanced histamine-mediated bronchial contractions of guinea pigs in vivo. Biochem Biophys Res Commun 1992;187:717-21.

20. Higgenbottam T, Jackson M, Rashdi T, Stewart S, Coutts C, Wallwork J. Lung rejection and bronchial hyperresponsivness to methacholine and ultrasonically nebulized distilled water in heart lung transplantation patients. Am Rev Respir Dis 1989;140:52-7.

21. Maurer JR, McLean PA, Cooper JD, Chamberlain DW, Grossman RF, Zamel N. Airway hyperactivity in patients undergoing lung and heart/lung transplantation. Am Rev Respir Dis 1989;139:1038-41.
22. Takuwa N, Takuwas Y, Yanagisawa M, Yamashita K, Masaki T. A novel vasoactive pepide endothelin stimulates mitogenesis through inositol lipid turnover in Swiss 3T3 fibroblasts. J Biol Chem 1989;264:7856-61.

23. Glassberger MK, Ergul A, Wanner A, Puett D. Endothelin-1 promotes mitogenesis in airway smooth muscle cells. Am. J Respir Cell Mol Biol 1994;10:31621.

24. Mattoli S, Mezzetti M, Riva G, Allegra L, Fasoli A. Specific binding of endothelin on human bronchial smooth muscle cells in culture and secretion of endothelin-like material from bronchial epithelial cells. Am J Respir Cell Mol Biol 1990;3:145-51.

25. Chang $\mathrm{H}$, Wu GJ, Wang SM, Hung CR. Plasma endothelin levels and surgically correctable pulmonary hypertension. Ann Thorac Surg 1993;55:450-8.

26. Kanse MK, Takahashi K, Warren JB, Ghatei M, Bloom SR. Glucocorticoids induce endothelin release from vascular smooth muscle cells but not endothelial cells. Eur J Pharmacol 1991;199:99-101.

27. Milne DS, Gascoigne AD, Wilkers J, et al. MHC class II and ICAM-1 expression and lymphocyte subsets in transbronchial biopsies from lung transplant recipients. Transplantation 1994;57:1762-6. 